\title{
Variability of bulk water vapor content in the marine cloudy boundary layers from microwave and near-infrared imagery
}

\author{
Luis F. Millán, Matthew D. Lebsock, and Joao Teixeira \\ Jet Propulsion Laboratory, California Institute of Technology, Pasadena, California, USA \\ Correspondence: Luis F. Millán (luis.f.millan@jpl.nasa.gov)
}

Received: 3 January 2019 - Discussion started: 14 February 2019

Revised: 17 May 2019 - Accepted: 14 June 2019 - Published: 4 July 2019

\begin{abstract}
This work uses the synergy of collocated microwave radiometry and near-infrared imagery to study the marine boundary layer water vapor. The Advanced Microwave Scanning Radiometer (AMSR) provides the total column water vapor, while the Moderate Resolution Imaging Spectroradiometer (MODIS) near-infrared imagery provides the water vapor above the cloud layers. The difference between the two gives the vapor between the surface and the cloud top, which may be interpreted as the boundary layer water vapor under certain conditions. As a byproduct of this algorithm, we also store cloud top information of the MODIS pixels used, a proxy for the inversion height, as well as the sea surface temperature and total column water vapor from the AMSR measurements. Hence, the AMSR-MODIS dataset provides several of the variables associated with the boundary layer thermodynamic structure. Comparisons against radiosondes and GPS radio occultation (GPSRO) data demonstrate the robustness of these boundary layer water vapor estimates. We explore the annual cycle of the number of observations as a proxy for stratus cloud amount, in well-known stratus regions; we then exploit the 16 years of AMSR-MODIS synergy to study for the first time the annual variations of the boundary layer water vapor in comparison to the sea surface temperature and the boundary layer cloud top height (equivalent to the inversion height) climatologies, and lastly we explore the climatological behavior of these variables on stratocumulus-to-cumulus transitions.
\end{abstract}

Copyright statement. (C) 2019 California Institute of Technology. Government sponsorship acknowledged.

\section{Introduction}

The boundary layer may be defined as the lower part of the troposphere that is directly influenced by the presence of the Earth's surface through turbulence. This layer mediates the exchanges of energy, momentum, water, carbon, and pollutants between the surface and the rest of the atmosphere and responds to surface forcing with a timescale of about an hour or less (Stull, 1988). Further, boundary layer processes are also intimately coupled with low clouds, such as stratocumulus. Stratocumulus is the most common cloud type covering around one-fifth of the Earth's surface (with mostly four-fifths of them located over the ocean), and they thus have a profound impact on Earth's energy balance, primarily through solar radiation reflection (e.g., Wood, 2012). As such, boundary layer processes are crucial for understanding cloud-climate feedback mechanisms (e.g., Teixeira et al., 2011).

Despite their importance, boundary layer processes are still not well represented in weather and climate models. For example, differences in the response of low clouds to warming scenarios are responsible for most of the spread in modelbased estimates of equilibrium climate sensitivity (Bony and Dufresne, 2005; Randall et al., 2007), and this spread appears to be attributable to how cloud, convective, and boundary layer processes are parameterized in such models (Boucher et al., 2013). However, one major issue in the development of accurate boundary layer parameterizations is the lack of global measurements.

The aim of this study is to show results from a $\sim 16$-year boundary layer column water vapor (BL-CWV) dataset derived from the synergy of microwave and near-infrared satellite imagery. Near-infrared imagery provides the water vapor above the clouds (by measuring the solar radiation re- 
flected near the $0.94 \mu \mathrm{m}$ water vapor band) while microwave radiometry provides information on the total column water vapor (by measuring at the water vapor absorption line near $22 \mathrm{GHz}$ ). As shown by Millán et al. (2016), the difference between their water vapor information provides an estimate of the BL-CWV when the cloud top is capped at the boundary layer top.

Variability in the boundary layer water vapor plays an important role in the evolution of clouds and precipitation. Some field campaigns (e.g., Crum and Stull, 1987; Weckwerth et al., 1996, 2004) have provided some information about its temporal and spatial distribution in a few regions, but its global variability and impact on clouds is still not properly understood. For example, subtle fluctuations in the vertical profile of water vapor appear to be associated with recurring stratocumulus and cumulus regimes (Betts and Boers, 1990). Further, several studies have shown that boundary layer water vapor is a critical quantity required for forecasting the initiation of convection (Crook, 1996; Ziegler and Rasmussen, 1998; Fabry, 2006; Martin and Xue, 2006). The combination of microwave and near-infrared imagery provides a unique capability to study the column water vapor in the planetary boundary layer (PBL).

\section{Measurements}

In this study, the AMSR-MODIS BL-CWV dataset version 2 is used. This dataset was produced by merging passive microwave and near-infrared CWV measurements as part of a NASA Making Earth System Data Records for Use in Research Environments (MEaSUREs) project. In short, BLCWV was found by subtracting the CWV above the clouds estimated by the Moderate Resolution Imaging Spectroradiometer (MODIS) from the total CWV estimated by Advanced Microwave Scanning Radiometer (AMSR) instruments. In particular, we use AMSR-E, AMSR-2, and AQUA MODIS data which allow us to estimate the BL-CWV from 2002 to date, except for a gap between April 2011 and July 2012 when AMSR-E stopped operating and AMSR-2 became operational. Note that no discrepancies or visible impacts were found in time series from these two instruments.

The AMSR instruments are dual-polarized conically scanning microwave radiometers with channels measuring in between 6.9 and $89 \mathrm{GHz}$. They provide day and night estimates of total CWV over the oceans with an estimated random error of $\sim 0.6 \mathrm{~mm}$ (Wentz and Meissner, 2000). Throughout this study we used the Remote Sensing Systems (REMSS) CWV retrievals, in particular version 7 , which aggregates these estimates to a $0.25^{\circ}$ spatial resolution. MODIS is an imaging spectroradiometer with 36 channels spread throughout the visible, near-infrared, and infrared. Here, we use version 6.0 except during December when cloud top height values were found to be unphysically large and inconsistent with the other months (Richard Frey, personal communication, 2018). In- stead, version 6.1 was used for all December months as recommended by the MODIS team. A full reprocessing of the AMSR-MODIS dataset using MODIS version 6.1 (or the latest MODIS version) is left for a future AMSR-MODIS version. In particular, we use the CWV estimated using nearinfrared channels. These CWV values have an estimated random error between $5 \%$ and $10 \%$ (Gao and Kaufman, 2003). These errors may have a solar zenith angle dependence as found for other MODIS products (i.e., Horváth et al., 2014; Grosvenor and Wood, 2014) and may worsen under cloud conditions; as such, we assume a $10 \%$ error throughout.

All these instruments orbit in tandem measuring the same volume of air within minutes of each other; that is, by design, these measurements are collocated; their equatorial crossing local time is $\sim 13: 30$. The MODIS retrievals of above cloud water vapor have poor height registration when the cloud is either thin or broken. To alleviate these biases several flags as well as proximity tests are applied to remove pixels with intrapixel heterogeneity and/or high clouds as specified by Millán et al. (2016). That is, we aim to identify homogeneous fields of liquid clouds in the MODIS data. Version 2 is the second public release of the AMSR-MODIS data. The only difference against version 1 is that high clouds are masked out using the cloud-phase optical properties. We only use the clouds which have been classified, by the cloud-thermodynamic-phase classification algorithm (Platnick et al., 2015), as liquid. This is a completely rewritten algorithm which instead of using a linear sequential structure, as in MODIS version 5, uses a voting discrimination logic to discriminate the cloud thermodynamic phase into ice, liquid, or undetermined (Marchant et al., 2016). AMSRMODIS version 1 instead screened only pixels where cirrus or aerosols were detected using the $1.38 \mu \mathrm{m}$ high-cloud flag (MYD35).

During the processing, the algorithm uses the MODIS level 2 products in their native grid (i.e., MODIS pixels with a $1 \mathrm{~km}$ size at nadir) before binning the data into a $1^{\circ}$ by $1^{\circ}$ grid. We produce daily and monthly files. Figure 1 shows an example of a BL-CWV daily as well as a monthly composite. It also shows its associated standard deviation as well as the number of single observations (MODIS pixels) used in each grid. Note that, as a by-product of the BL-CWV algorithm, we also save the cloud top height (BL-CTH), the cloud top pressure (BL-CTP), and the cloud top temperature (BL-CTT) of the MODIS pixels used, as well as the sea surface temperature (SST) and total CWV from AMSR in the same grid. As such, the AMSR-MODIS dataset provides several of the variables associated with the bulk boundary layer thermodynamic properties. Monthly files were constructed by aggregating the daily files neglecting pixels whose daily standard deviation was greater than $0.2 \mathrm{~cm}$. This threshold mostly rejects pixels in the intertropical convergence zone (ITCZ) where the boundary layer is not well defined. 
1 January 2005

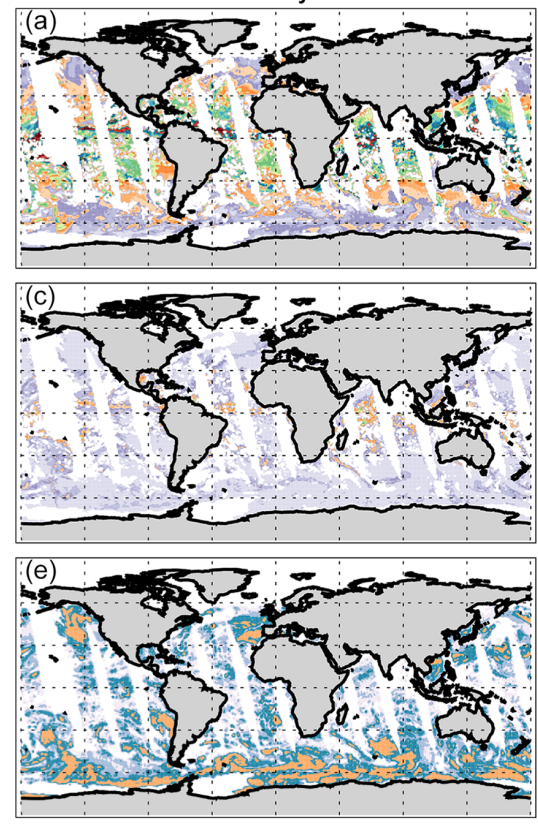

January 2005

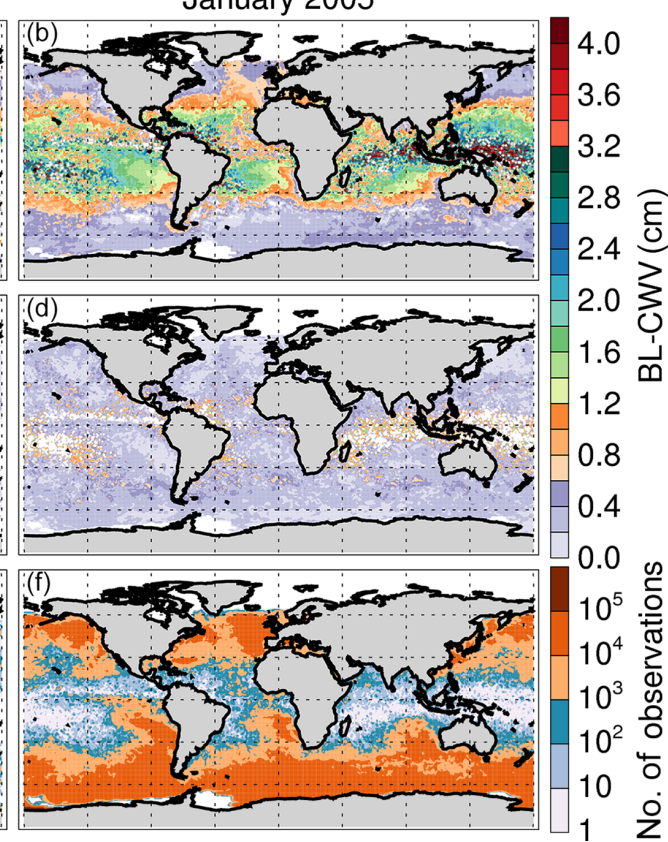

Figure 1. Example of daily (1 January 2005, a, c, e) and monthly (January 2005, b, d, f) composites of BL-CWV (a, b), its standard deviation (c, d), and the number of observations used $(\mathbf{e}, \mathbf{f})$.

\section{Comparisons with other observations}

In this section the accuracy of the AMSR-MODIS V2 BL$\mathrm{CWV}$ measurements is assessed through comparisons with radiosondes and Global Positioning System radio occultation (GPSRO) measurements. For these comparisons, we consider only observations that are collocated geographically and temporally. The coincidence criteria used vary and are stated in each subsection below. Note that throughout these comparisons we use the AMSR-MODIS level 2 data (that is, we use the data before gridding it) to allow a better comparison. In analyzing these comparisons, it is important to bear in mind that each of the observations used is sampling different volumes; sondes are precise in situ measurements which represent conditions at a local point, the AMSR-MODIS level 2 product estimates the boundary layer conditions within a pixel size of $1 \mathrm{~km}$ at nadir, and GPSRO samples through the limb of the atmosphere, averaging over large horizontal distances of $\sim 200 \mathrm{~km}$. Hence, geophysical variability will inevitably complicate the interpretation of such comparisons.

\subsection{Radiosondes}

In the comparison shown here we used sondes from two field campaigns: (1) the Alfred Wegener Institute (AWI) Polarstern laboratory campaign with more than 50 expeditions to the Arctic and the Antarctic (König-Langlo and Marx, 1997) since 1982 and (2) the Marine Atmospheric Radiation Measurement (ARM) GPCI Investigation of Clouds (MAGIC) campaign with approximately 20 round

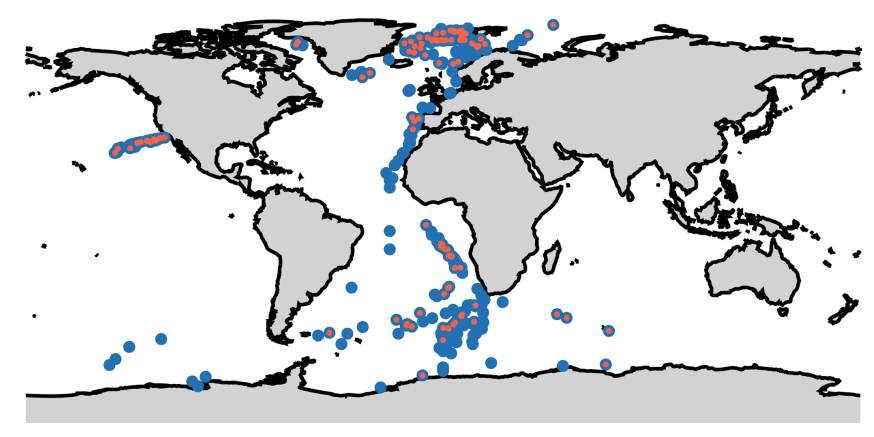

Figure 2. Map showing the geolocations of the radiosondes used in this study. Blue dots display the radiosondes that fulfill the criteria used in Fig. 3a while red dots display the subset that fulfills the criteria of Fig. 3b.

trips between Los Angeles and Honolulu during 2012-2013 (Kalmus et al., 2014; Zhou et al., 2015). Figure 2 shows the location of the radiosondes used.

To compute the BL-CWV from these measurements, we first identified the boundary layer inversion height and then integrated the specific humidity profile from that height to the surface. We use three different methods to find the inversion: the location of the minimum vertical gradient of specific humidity, the location of the minimum vertical gradient of relative humidity, and the location of the maximum vertical gradient of potential temperature. As in Millán et al. (2016), during the inversion height determination, we exclude all the data below $200 \mathrm{~m}$ or above $4 \mathrm{~km}$ to avoid artifacts caused by 


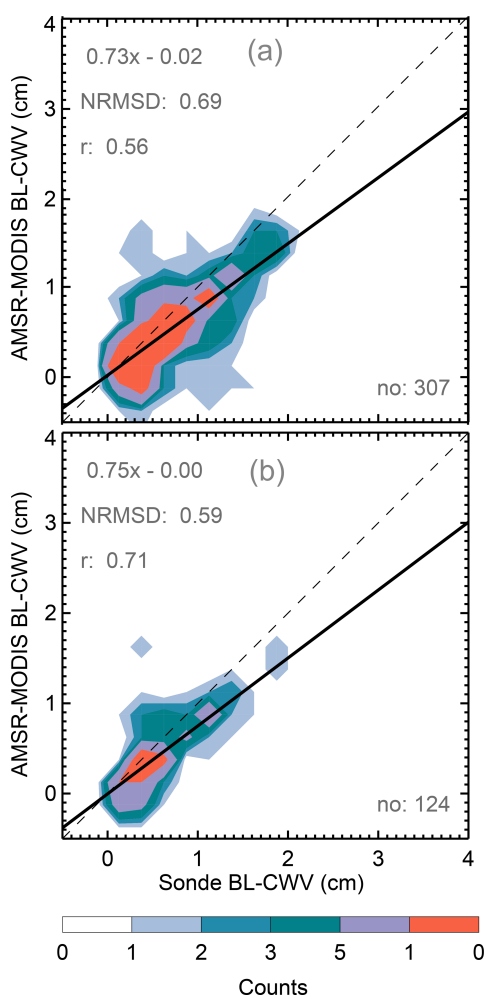

Figure 3. Sonde BL-CWV measurements scattered against the AMSR-MODIS BL-CWV estimates using $\pm 10 \mathrm{~km}$ and $\pm 6 \mathrm{~h}$ (a) and $\pm 1 \mathrm{~km}$ and $\pm 6 \mathrm{~h}$ (b) as coincidence criteria. The dashed black line is the one-to-one line. The solid black line displays a linear fit. The normalized root mean square deviation, the linear fit equation, the correlation coefficient $R$, and the total number of matches are shown.

temperature inversions near the surface as well as to avoid free-tropospheric features. Further, we use only robust inversions, that is, those inversions where the boundary layer inversion height estimates of the three methods agree within $200 \mathrm{~m}$, which mostly occur in stratus regions.

Figure 3a shows the scatter between AMSR-MODIS and radiosonde BL-CWV within $\pm 10 \mathrm{~km}$ and $\pm 6 \mathrm{~h}$. The best-fit line has a slope of 0.73 , a normalized (by the mean of the sondes values) root mean square deviation (NRMSD) of 0.69 , and a correlation coefficient of 0.56 , which suggests a reasonable but imperfect agreement between the two datasets. By decreasing the coincidence criteria distance from 10 to $1 \mathrm{~km}$ (Fig. 3b) it is possible to improve these metrics (the best-fit line slope becomes 0.75 , the NRMSD 0.59 , and the correlation coefficient 0.71 ), but the total number of matches decreases from 307 to 124 . Despite the scatter and the bias between the datasets, we find these results encouraging. The scatter was to be expected due the inherently noisy nature of the AMSR-MODIS product and because we do not know the extent to which the sonde measurements are representative of the average BL-CWV in the MODIS pixel.

\subsection{AMSR-GPSRO}

As cross validation, we use AMSR-GPSRO data. The GPSRO technique uses phase delays in the GPS signals collected from a receiver on board a low-Earth-orbiting satellite to derive profiles of refractivity. From these profiles, humidity in the middle and lower troposphere can be derived. In particular we use GPSRO data from the Constellation Observing System for Meteorology, Ionosphere, and Climate (COSMIC) constellation. A description of the measurements and the retrieval technique can be found in Kursinski et al. (1995), Kursinski and Hajj (2001), and Hajj et al. (2002). The accuracy of these measurements is around $10 \%$ to $20 \%$ below $7 \mathrm{~km}$ and $5 \%$ or better in the boundary layer (Kursinski et al., 1995). In particular we use version 2.6 of the JPL processing algorithm.

To compute the BL-CWV from GPSRO we follow a similar methodology as in the AMSR-MODIS dataset. First, we match up the GPSRO measurements with AMSR. As coincidence criteria we assume a match when any GPSRO lands within an AMSR footprint and $\pm 6 \mathrm{~h}$. Then, following Ao et al. (2012), we identified the boundary layer inversion height as the minimum vertical gradient of the refractivity, which corresponds to the height where the refractivity changes most rapidly, and integrate the humidity profile from that height upwards to compute the CWV above the inversion height. Lastly, we subtract these estimates from the AMSR total CWV to compute the BL-CWV. As such, a comparison between AMSR-MODIS and AMSR-GPSRO is, in essence, a comparison between MODIS water vapor above the clouds and the GPSRO water vapor above the BL inversion layer.

As an additional constraint we use the sharpness parameter, defined as the minimum refractivity gradient relative to the rms value of the gradient averaged over the bottom $6 \mathrm{~km}$ of the atmosphere (see Ao et al., 2012, for more information), to identify regions where the BL inversion is well defined. As discussed by Ao et al. (2012), we found that the sharpness parameter is largest over the eastern subtropical oceans where stratocumulus occur (see Fig. 4), with maximum average values of around 2.7 near the coast of Chile. The smallest sharpness parameters can be found in the ITCZ where the boundary layer is not well defined.

Figure 5a shows the scatter between AMSR-MODIS and GPSRO BL-CWV using as coincidence criteria $\pm 10 \mathrm{~km}$ and $\pm 6 \mathrm{~h}$ and a sharpness parameter value greater than 2.5 . Again, despite a fair amount of scatter and bias, the degree of agreement between the two datasets lends confidence to the usefulness of the AMSR-MODIS BL-CWV. By increasing the sharpness parameter requirement from 2.5 to 3.0 (Fig. 5b) the relationship between these two datasets improves with the best-fit line slope becoming 0.71 and the correlation coefficient 0.54 . The NRMSD (in this case normalized by the mean of the AMSR-GPSRO values) remains nearly identical at $\sim 0.5$. However, the total number of matches decreases from $\sim 23500$ to $\sim 750$. This improvement arises because 

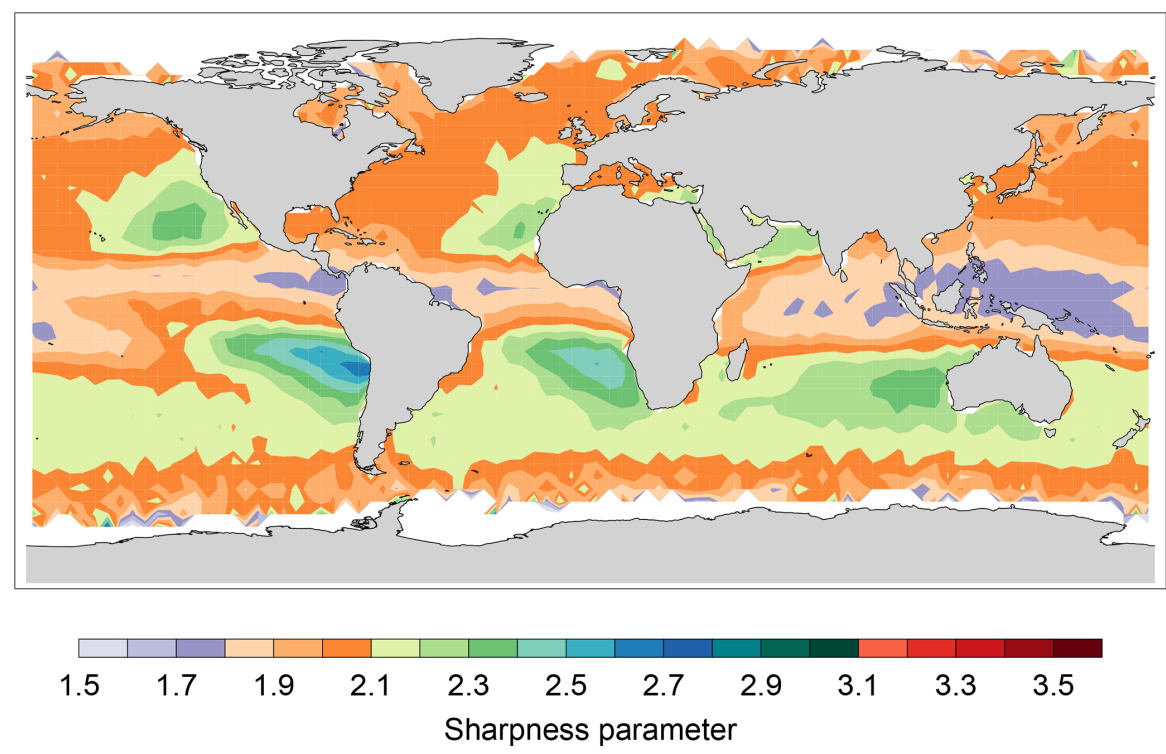

Figure 4. Sharpness parameter (relative minimum refractivity gradient) from 9 years (2006-2014) of the COSMIC data used on a $4^{\circ}$ by $4^{\circ}$ grid.

when using a larger sharpness parameter we are ensuring that most pairings are in the stratus regions (see Fig. 4 for reference) where the AMSR-MODIS technique should work better. A larger sharpness parameter also reduces the range of the BL-CWV comparison by excluding the high values found under cumulus regimes. This makes the comparison ranges (that is, in Fig. 5b) similar to the ones found in the sonde comparison where the sondes used are restricted to stratus regions by using the robust inversion criteria - that is, when the three different methods to find the inversion (explained in Sect. 3.1) agree within $200 \mathrm{~m}$.

Through these comparisons, a consistent picture emerges suggesting either an underestimation of the AMSR-MODIS BL-CWV or an overestimation of the radiosonde and GPSRO BL-CWV. An underestimation of the AMSR-MODIS BL-CWV has two possible reasons, an underestimation of the total CWV by AMSR and/or an overestimation of the MODIS CWV above the clouds. We found an excellent agreement between the AMSR total CWV versus the radiosondes measurements (not shown), with a strong correlation coefficient (0.94), a best-fit line slope of 1.06, and an rms deviation of $0.28 \mathrm{~cm}$. This suggest that there may be an overestimation of the MODIS CWV above the clouds. The retrieval of BL-CWV above clouds is complicated by the fact that the near-IR radiation penetrates the cloud layer. The multiple scattering of the light within the cloud increases the optical path length of the cloud and should result in an overestimate in water vapor above the clouds. The MODIS algorithm does not account for this effect and as a result the cloudy pixels are flagged with marginal quality assurance. The overestimation of the MODIS CWV above the clouds could lead to negative values in the AMSR-MODIS dataset (as can be seen in Fig. 5a). However, we do not recommend that these negatives values are excluded from any analysis of the AMSR-MODIS dataset because some negative values will be due to the noisy nature of the MODIS measurements over cloudy pixels, and excluding those will lead to biasing high.

We believe that a consistent overestimation of the radiosonde and GPSRO BL-CWV is unlikely due to the sharp gradients associated with the boundary layer inversion, but we do suspect that uncertainties in determining such inversion are one likely culprit causing some of the scatter shown in Figs. 3 and 5. In some cases, it is difficult to determine the boundary layer inversion height in the radiosonde and in the GPSRO data because several alternating dry and moist layers may be present in the measurements. In those cases, there is no guarantee that the algorithms chosen will identify the correct height, choosing instead a residual layer or a dry intrusion, which will lead to an overestimation or underestimation, respectively, of the BL-CWV estimated by the radiosondes or GPSRO data. von Engeln and Teixeira (2013) have shown that using different methods to estimate the boundary layer inversion height can lead to significantly different results even when using the same original datasets. For example, a consistent overestimation of the boundary layer inversion height (at least in the radiosonde cases) might be possible because as shown by Seidel et al. (2010) finding the inversion using the location of the minimum (maximum) vertical gradient of relative humidity (potential temperature) consistently yields higher PBL height estimates than other methods. Nevertheless, considering the boundary layer geophysical variability (for example, the short response time of the boundary layer), the different sampling volumes associated 


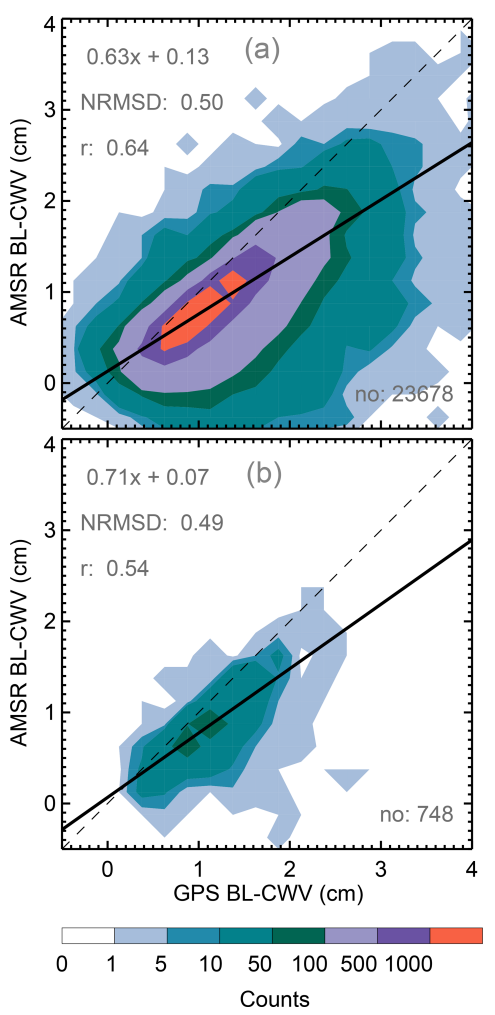

Figure 5. AMSR-GPSRO BL-CWV measurements scattered against the AMSR-MODIS BL-CWV measurements using $\pm 10 \mathrm{~km}, \pm 6 \mathrm{~h}$, and a sharpness parameter greater than 2.5 (a) and $\pm 10 \mathrm{~km}, \pm 6 \mathrm{~h}$, and a sharpness parameter greater than 3 (b) as coincidence criteria. The dashed black line is the one-to-one line. The solid black line displays a linear fit. The normalized root mean square deviation, the linear fit equation, the correlation coefficient $R$, and the total number of matches are shown.

with each technique, and the uncertainties in determining the boundary layer inversion height, we conclude that AMSRMODIS BL-CWV, sondes, and GPSRO BL-CWV measurements are in good agreement.

\section{Results}

\subsection{Climatology of stratus amount}

Figure 6 shows the total number of observations found throughout the AMSR-MODIS dataset from 2002 to 2017. A high number of observations means that uniform liquid cloud fields were found consistently in such areas and can be interpreted as a qualitative proxy for stratus cloud fraction amount. Overlaid on this map are contours displaying the mean vertical velocity at $500 \mathrm{hPa}\left(\omega_{500}\right)$ from ERA-Interim (Dee et al., 2011) showing regions of large-scale subsidence and convective regions. As expected, a high number of observations are found in subtropical eastern oceans, in regions where stratocumulus clouds frequently occur (e.g., Klein and
Table 1. Geographical extent of the regions used in this study.

\begin{tabular}{ll}
\hline Region & Geographical boundaries \\
\hline Peruvian & $10-20^{\circ} \mathrm{S}, 80-90^{\circ} \mathrm{W}$ \\
Namibian & $10-20^{\circ} \mathrm{S}, 0-10^{\circ} \mathrm{E}$ \\
Californian & $20-30^{\circ} \mathrm{N}, 120-130^{\circ} \mathrm{W}$ \\
Canarian & $15-25^{\circ} \mathrm{N}, 25-35^{\circ} \mathrm{W}$ \\
\hline
\end{tabular}

Hartmann, 1993; Wood, 2012). These subtropical regions are characterized by relatively cold sea surface temperature, strong subsidence, and well-defined temperature inversions at the boundary layer (see, for example, the high values of the sharpness parameter shown in Fig. 4). A high number of observations can also be found in regions where stratus clouds frequently occur (e.g., Teixeira, 1999) like over the arctic, over the Southern Ocean, and off the east coast of the continents in the Northern Hemisphere. The lowest number of observations are found in the deep tropics, particularly in convective regions where the presence of nonuniform cumulus and also obscuring high clouds associated with deep convection decreases considerably the probability of finding uniform liquid cloud fields. Hence, the observations in this tropical region, where the boundary layer is not well defined, are not particularly reliable.

Climatological annual cycles of the number of observations for the regions shown in Fig. 6 are shown in Fig. 7. These regions are subtropical stratus locations taken from Klein and Hartmann (1993) and listed in Table 1 for clarity. The annual cycles in the Californian and Canarian regions are similar to maxima during July and the peak lasting from June to August; however, the Canarian region has far fewer observations (i.e., unobscured stratus clouds). The annual cycle is notably stronger in the Peruvian and Namibian regions with maxima during August and the peak lasting from June to November. Overall, the annual cycle of the number of observations is in good qualitative agreement with the climatology of marine stratus compiled from ship-based weather observations by Klein and Hartmann (1993) or the climatology of low clouds derived from 5 years of CloudSat and CALIPSO data by Muhlbauer et al. (2014).

Previous studies have suggested that the seasonality of this type of clouds largely follows the lower tropospheric stability (LTS) (Klein and Hartmann, 1993; Richter, 2004; Wood and Bretherton, 2006; Richter and Mechoso, 2006). Figure 8 shows the annual cycle of LTS taken from the ERA-Interim reanalysis. LTS is defined as the difference between potential temperature at $700 \mathrm{hPa}$ and the temperature at the surface. The LTS relation can be theoretically derived from the energy balance equation for the boundary layer (Chung et al., 2012) and can be thought of as a proxy for the strength of the inversion capping the boundary layer; in principle, a strong inversion is more effective at trapping humidity in the boundary layer, which will gradually accumulate and reach 


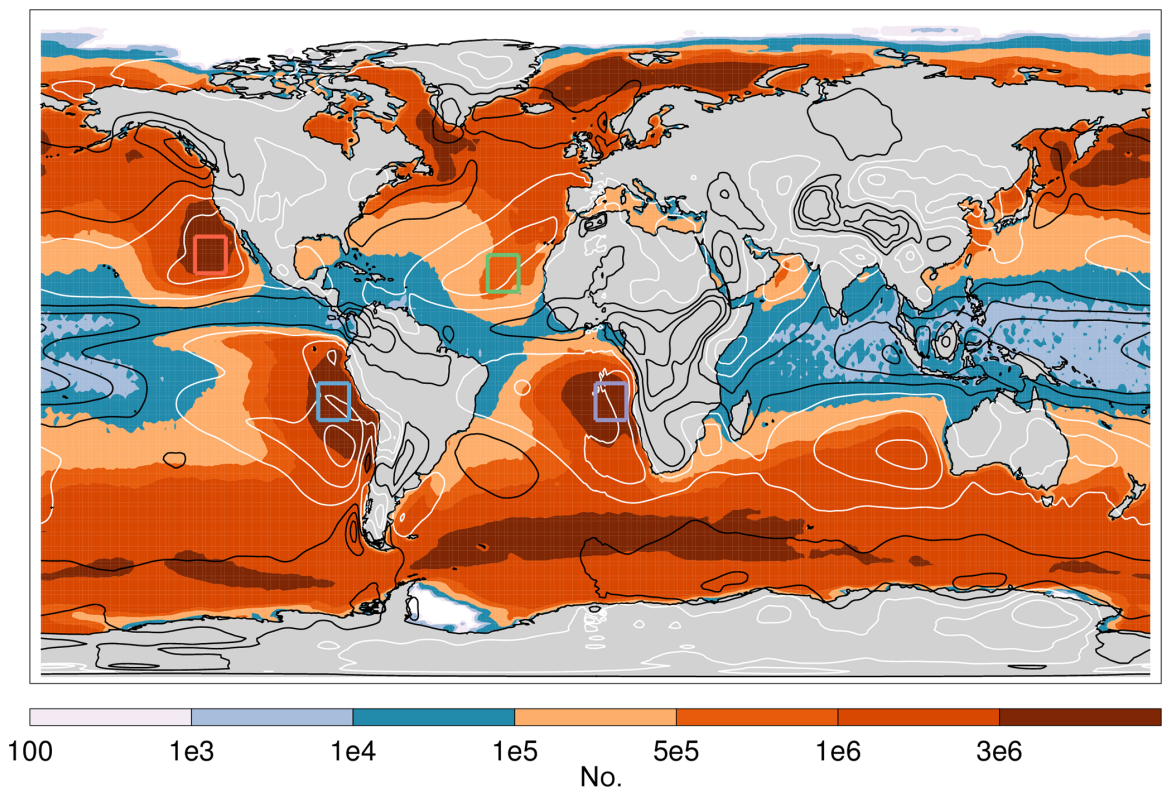

Figure 6. Number of observations found in the AMSR-MODIS dataset over 2002 to 2017. Overlaid contours display air vertical velocity at $500 \mathrm{hPa}\left(\omega_{500}\right)$ from ERA-Interim, with white contours at $0.01,0.03$, and $0.05 \mathrm{~Pa} \mathrm{~s}^{-1}$ denoting sinking of air and black contours -0.05 , -0.03 , and $-0.01 \mathrm{Pas}^{-1}$ denoting rising of air. A 2-D smoothing has been applied to the $\omega_{500}$ fields. Color rectangular boxes identify regions with a high number of stratocumulus clouds. These locations are adopted from Klein and Hartmann (1993).

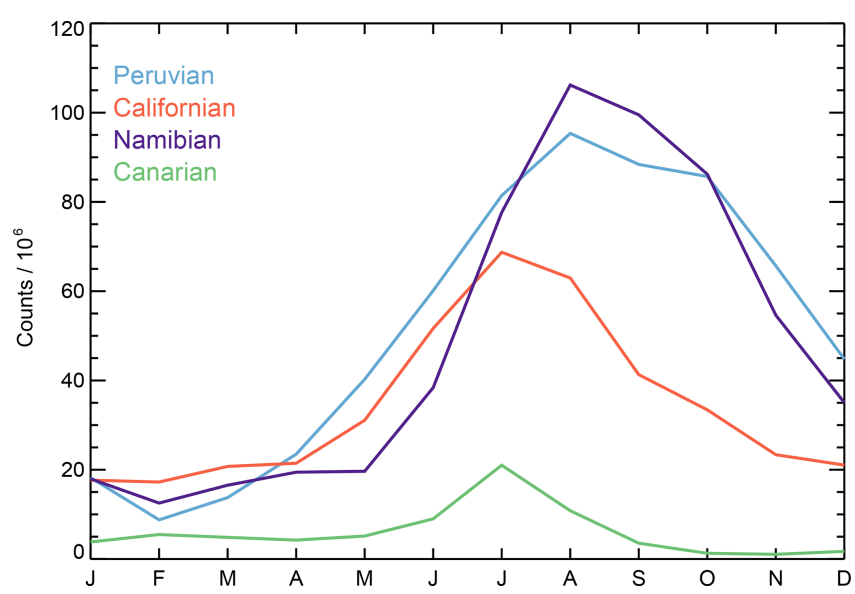

Figure 7. Annual cycle of the total AMSR-MODIS number of observations for the regions delimited in Fig. 6 by the rectangular boxes.

saturation, hence enhancing cloud cover. As displayed, the Canarian LTS annual cycle is similar to the Californian one but $\sim 4 \mathrm{~K}$ lower throughout the year, which as suggested by Klein and Hartmann (1993) may result in the significant reduction of stratus in such a region. These LTS annual cycles are similar to the ones shown or described by Klein and Hartmann (1993). More interestingly, Fig. 8 also shows the correlation coefficient between the number of observations and LTS in each of these regions. As expected, relatively high values can be found in most regions $(0.77,0.8,0.91$, and 0.93 for the Californian, Canarian, Namibian, and Peruvian regions respectively). Interannual correlations, that is, correlations based upon the monthly time series as opposed to the climatological data, also display relatively high correlations, with values of $0.76,0.77,0.87$, and 0.85 for the Californian, Canarian, Namibian, and Peruvian regions, respectively. Note that for each region, ERA-Interim data from the nearest synoptic time (00:00, 06:00, 12:00, 18:00 UT) to the measurement local time were used; furthermore, other parameters (MODIS CTP, AMSR SST, ERA-Interim $\omega_{500}$, and ERA-Interim surface pressure) were analyzed in a similar manner but none of them were strongly correlated with the number of observations across the four regions used here.

\subsection{Climatology of BL-CWV}

Figure 9 shows the annual cycle for BL-CWV, SST, and BLCTH taken from the AMSR-MODIS dataset. Only the Peruvian and Namibian region display a significant BL-CWV annual cycle with maximum-to-minimum differences of 8 and $6 \mathrm{~mm}$, respectively, displaying a clear sinusoidal signature (specially in the Peruvian region) with maxima in February and minima during the fall. In the other regions, the maximum-to-minimum BL-CWV difference is only $3 \mathrm{~mm}$ throughout the year with no well-defined minima or maxima. All regions display a clear SST annual cycle, with maximumto-minimum differences close to $\sim 4 \mathrm{~K}$. As with the LTS annual cycles shown in Fig. 8, these SST annual cycles agree with the ones shown or described by Klein and Hartmann (1993). The BL-CTH annual cycles display a lot of variabil- 


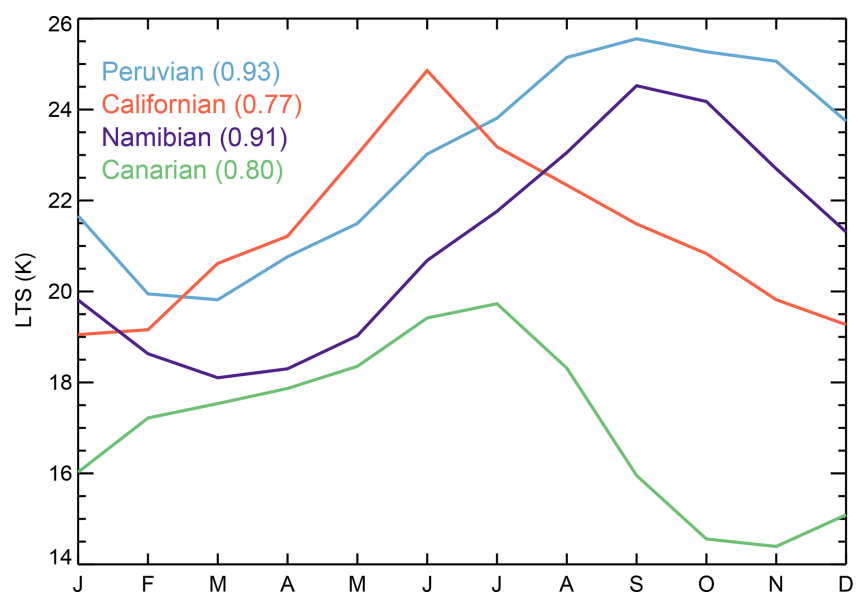

Figure 8. Annual cycle of LTS for the regions delimited in Fig. 6 by the rectangular boxes. The numbers in brackets are the correlation coefficients between the annual cycle of the number of observations (shown in Fig. 7) and these LTS cycles.

ity, with no clear discernible pattern among the regions. The Canarian and Peruvian regions show the greatest maximum and minimum differences with 1.5 and $0.9 \mathrm{~km}$ respectively.

Table 2 shows the climatological and interannual correlation coefficients between the BL-CWV annual cycle and the ones found for BL-CTH, SST, LTS, and the number of observations. Only the Peruvian and Namibian regions display high correlation coefficient (that is, $|r|>0.7$ ), at least in the climatological correlations, between these parameters. In those two regions the seasonal cycle strongly follows a cycle of modulation of the SST, which is negatively correlated with the LTS and positively correlated with boundary layer depth, and bulk boundary layer water vapor content. This pattern is also true with weaker correlation in the Californian and Canarian regions which may be due to the smaller seasonal amplitude of the cycles in these regions.

Figure 10 shows the measured annual cycle for BL-CWV, as well as the derived one from a simple well-mixed boundary layer model as the one described by Millán et al. (2016), assuming a surface relative humidity of $80 \%$ and using the AMSR SST, the MODIS CTH, and the ERA-Interim surface pressure as constraints. These cycles were both normalized by their respective maximum values. The modeled BL-CWV does resemble the BL-CWV measured one, particularly in the Peruvian and Namibian regions, where the correlation coefficients between the modeled and measured BL-CWV are 0.99 and 0.95 respectively. This suggests than in the most robust subtropical stratocumulus regions key properties such as water vapor content can be represented by a simple mixedlayer model. Note, however, that the well-mixed model consistently overestimates the measured BL-CWV in part due to the underestimation of the AMSR-MODIS product as shown by Figs. 3 and 5 and in part because of the simplistic repre-

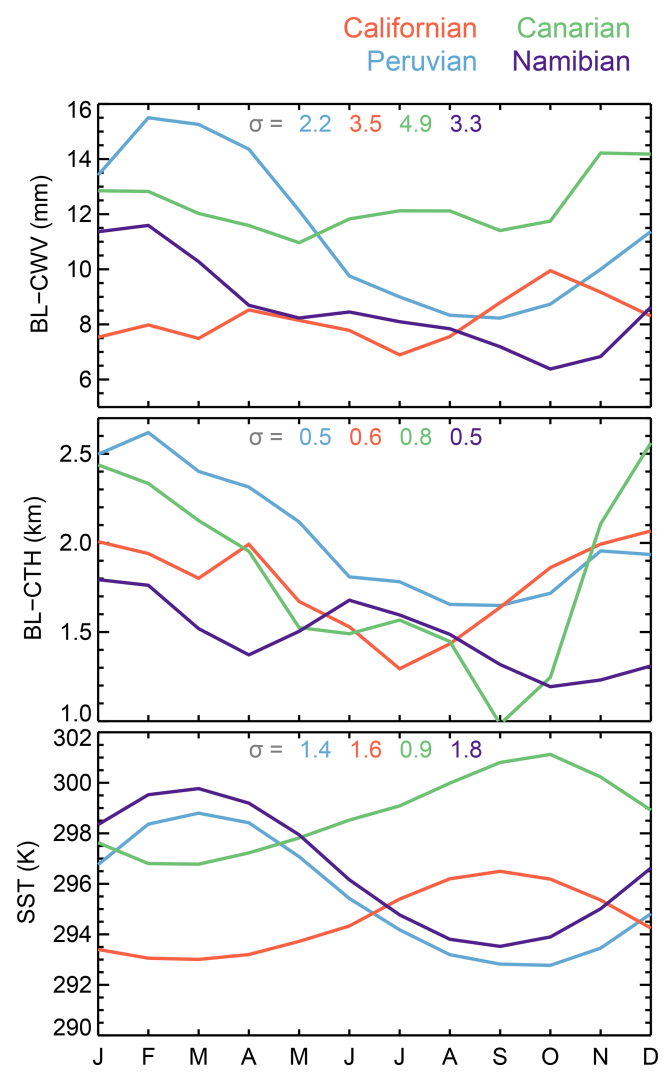

Figure 9. Seasonal cycle of BL-CWV, BL-CTH, and SST, for the regions delimited in Fig. 6 by the rectangular boxes. The numbers shown are the average standard deviation per region.

Table 2. Climatological (top) and interannual (bottom) correlation coefficients between BL-CWV and several other variables. Bold text indicates a high correlation coefficient $(|r|>0.7)$.

\begin{tabular}{lcrrr}
\hline Region & SST & LTS & BL-CTH & $\begin{array}{r}\text { Number of } \\
\text { observations }\end{array}$ \\
\hline Peruvian & $\mathbf{0 . 9 5}$ & $\mathbf{- 0 . 9 5}$ & $\mathbf{0 . 9 6}$ & $\mathbf{- 0 . 9 8}$ \\
Namibian & $\mathbf{0 . 8 1}$ & $\mathbf{- 0 . 7 6}$ & $\mathbf{0 . 8 1}$ & $-\mathbf{0 . 7 2}$ \\
Californian & 0.37 & -0.27 & 0.48 & -0.36 \\
Canarian & 0.06 & -0.55 & $\mathbf{0 . 7 2}$ & -0.26 \\
\hline Peruvian & $\mathbf{0 . 9 5}$ & $\mathbf{- 0 . 8 8}$ & $\mathbf{0 . 8 6}$ & $-\mathbf{0 . 9 2}$ \\
Namibian & $\mathbf{0 . 7 5}$ & -0.63 & $\mathbf{0 . 8 2}$ & -0.61 \\
Californian & 0.44 & -0.31 & 0.63 & -0.27 \\
Canarian & 0.12 & -0.22 & 0.61 & -0.10 \\
\hline
\end{tabular}

sentation of the boundary layer humidity profile by such a model.

\subsection{Stratocumulus-to-cumulus transitions}

To further analyze the data, we focused on typical Stratocumulus-Cumulus transects. In these transects, stratiform clouds typically reside above relatively cold waters near 


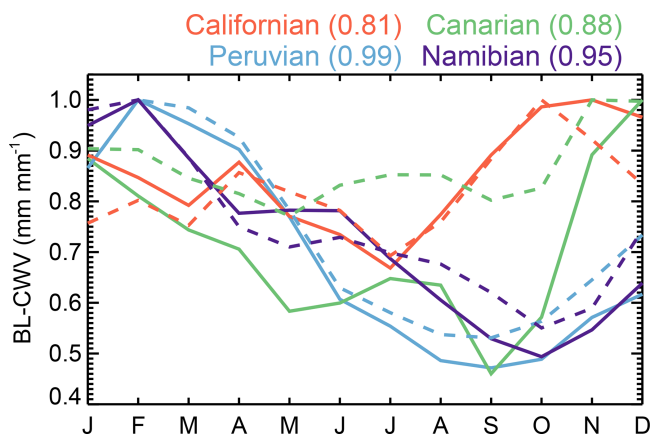

Figure 10. Normalized measured seasonal cycle of BL-CWV (solid lines), as well as derived from simple mixed-layer model (dash lines) for the regions delimited in Fig. 6 by the rectangular boxes. The numbers in brackets are the correlations coefficient between the measured BL-CWV and the modeled one.

the coasts, below subsiding air, in shallow and normally well mixed boundary layers capped by a strong temperature inversion. As trade winds advect air toward the Equator, the subsidence weakens and the sea surface gradually warms, leading to an increase in heat and moisture fluxes and a rising and weakening of the inversion, resulting in trade wind shallow convective clouds and eventually in deep convective clouds (e.g., Teixeira et al., 2011).

Figure 11 displays the transects used. These transects were taken from Sandu et al. (2010), in particular the ones constructed using gridded mean climatological meteorological fields. Figure 12 shows the climatological SST, BL-CWV, and BL-CTH along these transects. The Californian and Canarian transects display data from June, July, and August while the Peruvian and Namibian transects display data for September, October, and November. These months correspond to the ones used by Sandu et al. (2010) during their trajectory analysis. These are the periods where Klein and Hartmann (1993) found the highest cloud fraction in the stratocumulus region on each oceanic basin.

The Californian and Canarian transects display the expected behavior with warmer temperatures towards the Equator resulting in a systematic deepening and moistening of the boundary layer. The boundary layer cloud top height starts as shallow as 1.4 and deepens up to 2.4 or $2.5 \mathrm{~km}$ in the Californian and Canarian transects respectively. Similarly, the boundary layer column water starts as dry as 7 or 11 and moistens up to 22 or $25 \mathrm{~mm}$, respectively. On the other hand, the Namibian and Peruvian transects do not display this canonical picture. Notably these Southern Hemisphere transects each cross the Equator. In the Namibian transect, despite a clear increase in SST along it, BL-CTH remains constant, at around $1.5 \mathrm{~km}$, throughout its entire length. On the other hand, BL-CWV shows a systematic moistening, starting as dry as 7 and going as high as $20 \mathrm{~mm}$. In the Peruvian transect, despite a clear increase in SST, BL-CTH and BLCWV remain constant (with values of $1.9 \mathrm{~km}$ and $10 \mathrm{~mm}$ ) up

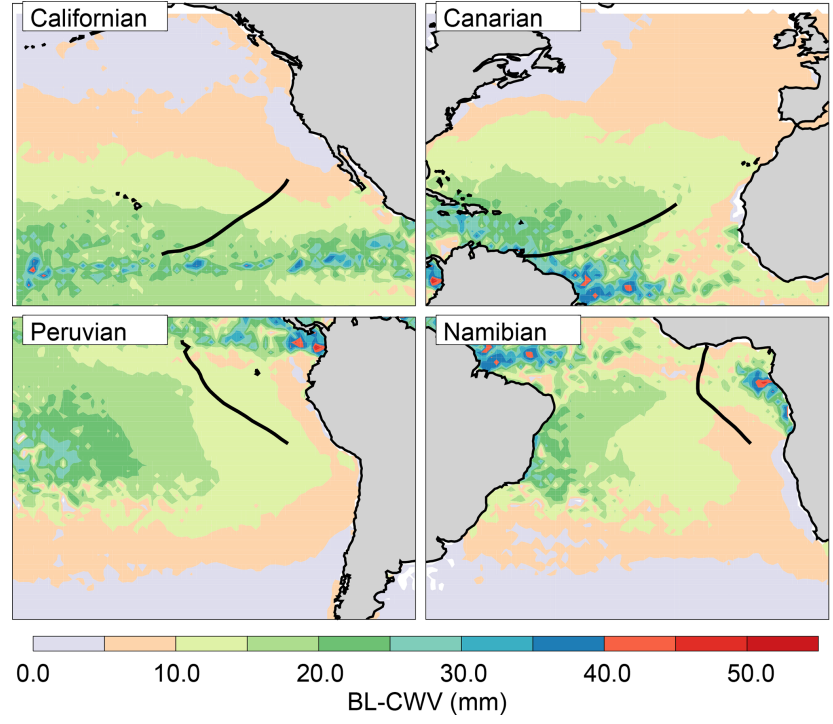

Figure 11. Transects along the climatological streamlines used in this study (taken from Sandu et al., 2010). The contours show the climatological composite for all the AMSR-MODIS BL-CWV data available.

to $2500 \mathrm{~km}$ into the transect, only deepening and moistening steeply due to a sharp jump in the SSTs as the transect crosses the ITCZ.

\section{Summary}

The synergy of AMSR and MODIS measurements provides the opportunity of estimating for the first time the column of water vapor inside the marine boundary layer, although the technique is limited to homogeneous cloud fields during daylight. The boundary layer water vapor information results from combining AMSR estimates of total column water vapor, which are unaffected by clouds, with those derived from MODIS near-infrared channels using solar radiation reflected by clouds, which estimate the water vapor above the clouds. In this study we discussed results from the second public release of the AMSR-MODIS dataset. The AMSRMODIS dataset is available in daily and monthly composites with a $1^{\circ}$ by $1^{\circ}$ resolution. Monthly files were constructed by aggregating the daily files but disregarding daily pixels with standard deviation greater than $0.2 \mathrm{~cm}$. This threshold mostly rejects pixels in the ITCZ where the boundary layer is not well defined. As a by-product of the BL-CWV algorithm, the AMSR-MODIS dataset also provides the BL-CTH, BLCTP, and the BL-CTT of the MODIS pixels used, as well as the associated SST and total CWV from AMSR. As such, the AMSR-MODIS dataset provides many of the variables of interest for boundary layer studies.

We exploited 16 years of collocated AMSR and MODIS measurements to study the behavior of the number of observations as well as the behavior of the BL-CWV over 


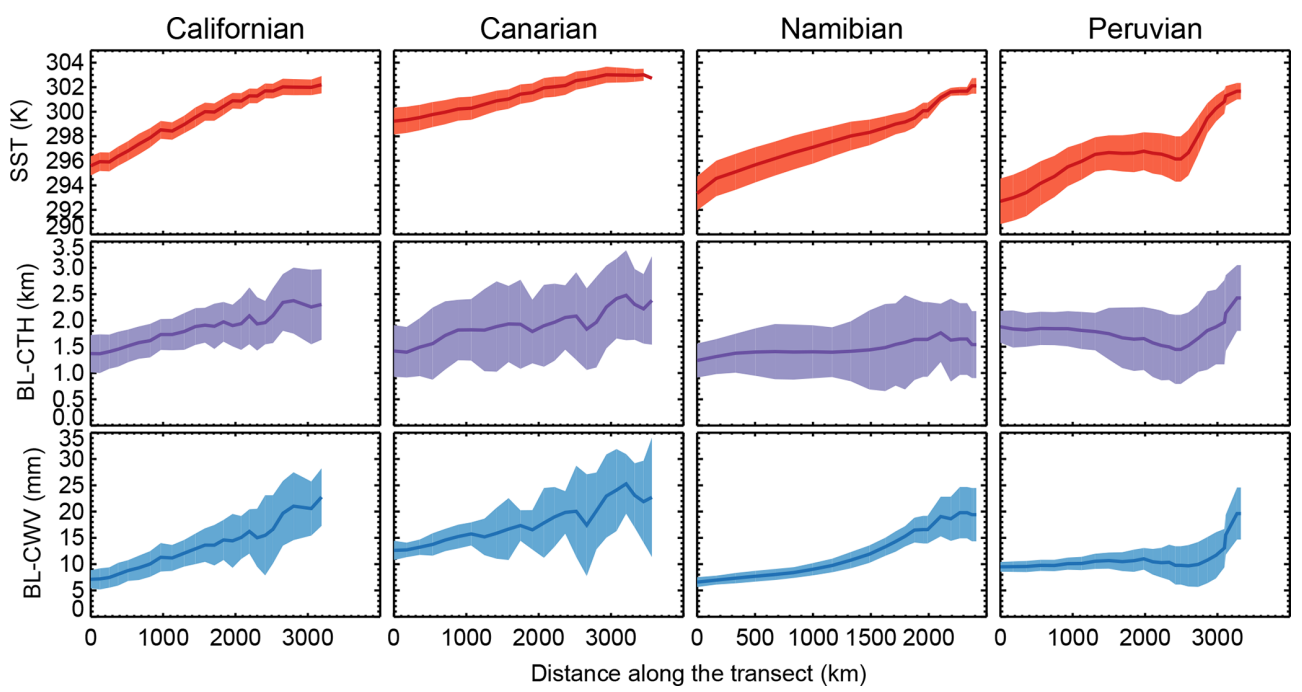

Figure 12. Climatological SST, BL-CTH, and BL-CWV along the transects shown in Fig. 11. The envelopes display the standard deviation.

well-known stratus regions. Further, we also study the stratocumulus-to-cumulus transitions. The main findings can be summarized as follows.

- Comparisons between AMSR-MODIS BL-CWV against radiosondes and AMSR-GPSRO data were undertaken. A consistent picture emerges suggesting an underestimation of the AMSR-MODIS BL-CWV measurements most likely due to an overestimation by the water vapor column above the clouds by MODIS. However, considering the geophysical variability of the boundary layer, the different sampling volumes of each technique, and the uncertainties associated with determining the inversion height in the sondes and AMSR-GPSRO boundary layer estimates, we believe that the comparisons demonstrate the skill of the AMSR-MODIS boundary layer water vapor estimates to detect variability.

- In well-know stratus regions, the annual cycle of the number of observations (a qualitative proxy for stratus cloud fraction amount) is in good qualitative agreement with the climatology of marine stratus compiled from ship-based weather observations by Klein and Hartmann (1993) and the climatology of low clouds derived from 5 years of CloudSat and CALIPSO data by Muhlbauer et al. (2014). Furthermore, as previous studies have suggested, in all the stratus regions the number of observations is well correlated with lower tropospheric stability showing the inclination of stratus (homogeneous clouds fields) to form under a strong capping inversion layer.

- In the most robust subtropical stratocumulus regions key properties such as water vapor content can be represented by a simple mixed-layer model.
- The Californian and Canarian stratocumulus-tocumulus transitions displayed the canonical view of these transects with a gradual deepening and moistening of boundary layer as the sea surface temperature warms up towards the Equator. On the other hand, the Namibian and Peruvian transects do not display this canonical behavior.

In summary, these results demonstrate that the AMSRMODIS dataset provides useful information regarding the marine boundary layer, particularly over stratus regions. Further, the multisensor nature of the analysis demonstrates that there exists more information on boundary layer water vapor structure in the satellite observing system than is commonly assumed when considering the capabilities of single instruments.

Data availability. The AMSR-MODIS dataset can be found on the NASA Goddard Space Flight Center Earth Sciences (GES) Data and Information Services Center (DISC) website (http://disc.sci.gsfc.nasa.gov/, last access: December 2018) with https://doi.org/10.5067/MEASURES/AMDBLWV2 (Millán et al., 2018a) and https://doi.org/10.5067/MEASURES/AMMBLWV2 (Millán et al., 2018b) digital object identifiers for the daily and monthly data respectively. The data are stored in netcdf version 4 format. ERA-Interim reanalysis fields can be found at the ECMWF website (http://apps.ecmwf.int/datasets/, last access: December 2018).

Author contributions. LFM wrote the AMSR-MODIS algorithm and carried out the analyses. MDL and JT provided scientific expertise throughout all stages of the research. 
Competing interests. The authors declare that they have no conflict of interest.

Acknowledgements. The research described in this study was carried out by the Jet Propulsion Laboratory, California Institute of Technology, under contract with the National Aeronautics and Space Administration.

Review statement. This paper was edited by Johannes Quaas and reviewed by two anonymous referees.

\section{References}

Ao, C. O., Waliser, D. E., Chan, S. K., Li, J.-L., Tian, B., Xie, F., and Mannucci, A. J.: Planetary boundary layer heights from GPS radio occultation refractivity and humidity profiles, J. Geophys. Res.-Atmos., 117, d16117, https://doi.org/10.1029/2012JD017598, 2012.

Betts, A. K. and Boers, R.: A Cloudiness Transition in a Marine Boundary Layer, J. Atmos. Sci., 47, 1480, https://doi.org/10.1175/15200469(1990)047<1480:ACTIAM>2.0.CO;2, 1990.

Bony, S. and Dufresne, J.-L.: Marine boundary layer clouds at the heart of tropical cloud feedback uncertainties in climate models, Geophys. Res. Lett., 32, L20806, https://doi.org/10.1029/2005g1023851, 2005.

Boucher, O., Randall, D., Artaxo, P., Bretherton, C., Feingold, G., Forster, P., Kerminen, V.-M., Kondo, Y., Liao, H., Lohmann, U., Rasch, P., Satheesh, S., Sherwood, S., Stevens, B., and Zhang, X.: Clouds and Aerosols, book section 7, 571-658, Cambridge University Press, Cambridge, UK and New York, NY, USA, https://doi.org/10.1017/CBO9781107415324.016, 2013.

Chung, D., Matheou, G., and Teixeira, J.: Steady-State LargeEddy Simulations to Study the Stratocumulus to Shallow Cumulus Cloud Transition, J. Atmos. Sci., 69, 3264-3276, https://doi.org/10.1175/jas-d-11-0256.1, 2012.

Crook, N. A.: Sensitivity of Moist Convection Forced by Boundary Layer Processes to Low-Level Thermodynamic Fields, Mon. Weather Rev., 124, 1767-1785, https://doi.org/10.1175/15200493(1996)124<1767:somcfb>2.0.co;2, 1996.

Crum, T. D. and Stull, R. B.: Field Measurements of the Amount of Surface Layer Air versus Height in the Entrainment Zone, J. Atmos. Sci., 44, 2743-2753, https://doi.org/10.1175/15200469(1987)044<2743:fmotao>2.0.co;2, 1987.

Dee, D. P., Uppala, S. M., Simmons, A. J., Berrisford, P., Poli, P., Kobayashi, S., Andrae, U., Balmaseda, M. A., Balsamo, G., Bauer, P., Bechtold, P., Beljaars, A. C. M., van de Berg, L., Bidlot, J., Bormann, N., Delsol, C., Dragani, R., Fuentes, M., Geer, A. J., Haimberger, L., Healy, S. B., Hersbach, H., Hólm, E. V., Isaksen, L., Kållberg, P., Köhler, M., Matricardi, M., McNally, A. P., Monge-Sanz, B. M., Morcrette, J.-J., Park, B.-K., Peubey, C., de Rosnay, P., Tavolato, C., Thépaut, J.-N., and Vitart, F.: The ERA-Interim reanalysis: configuration and performance of the data assimilation system, Q. J. Roy. Meteor. Soc., 137, 553-597, https://doi.org/10.1002/qj.828, 2011.
Fabry, F.: The Spatial Variability of Moisture in the Boundary Layer and Its Effect on Convection Initiation: ProjectLong Characterization, Mon. Weather Rev., 134, 79-91, https://doi.org/10.1175/mwr3055.1, 2006.

Gao, B.-C. and Kaufman, Y. J.: Water vapor retrievals using Moderate Resolution Imaging Spectroradiometer (MODIS) near-infrared channels, J. Geophys. Res.-Atmos., 108, 4389, https://doi.org/10.1029/2002JD003023, 2003.

Grosvenor, D. P. and Wood, R.: The effect of solar zenith angle on MODIS cloud optical and microphysical retrievals within marine liquid water clouds, Atmos. Chem. Phys., 14, 7291-7321, https://doi.org/10.5194/acp-14-7291-2014, 2014.

Hajj, G., Kursinski, E. R., Romans, L. J., Bertiger, W. I., and Leroy, S. S.: A technical description of atmospheric sounding by GPS occultation, J. Atmos. Sol.-Terr. Phy., 64, 451-469, https://doi.org/10.1016/S1364-6826(01)00114-6, 2002.

Horváth, Á., Seethala, C., and Deneke, H.: View angle dependence of MODIS liquid water path retrievals in warm oceanic clouds, J. Geophys. Res.-Atmos., 119, 8304-8328, https://doi.org/10.1002/2013jd021355, 2014.

Kalmus, P., Lebsock, M., and Teixeira, J.: Observational Boundary Layer Energy and Water Budgets of the Stratocumulusto-Cumulus Transition, J. Climate, 27, 9155-9170, https://doi.org/10.1175/jcli-d-14-00242.1, 2014.

Klein, S. and Hartmann, D. L.: The Seasonal Cycle of Low Stratiform Clouds, J. Climate, 6, 1587-1605, https://doi.org/10.1175/15200442(1993)006<1587:TSCOLS>2.0.CO;2, 1993.

König-Langlo, G. and Marx, B.: The meteorological information system at the Alfred-Wegener-Institute, Climate and Environment Database Systems, edited by: Lautenschlager, M. and Reinke, M., Springer International Series in Engineering and Computer Science, Vol. 386, 117-126, Springer, Boston, MA, 1997.

Kursinski, E. R. and Hajj, G. A.: A comparison of water vapor derived from GPS occultations and global weather analyses, J. Geophys. Res.-Atmos., 106, 1113-1138, https://doi.org/10.1029/2000JD900421, 2001.

Kursinski, E. R., Hajj, G. A., Hardy, K. R., Romans, L. J., and Schofield, J. T.: Observing tropospheric water vapor by radio occultation using the Global Positioning System, Geophys. Res. Lett., 22, 2365-2368, https://doi.org/10.1029/95GL02127, 1995.

Marchant, B., Platnick, S., Meyer, K., Arnold, G. T., and Riedi, J.: MODIS Collection 6 shortwave-derived cloud phase classification algorithm and comparisons with CALIOP, Atmos. Meas. Tech., 9, 1587-1599, https://doi.org/10.5194/amt-9-1587-2016, 2016.

Martin, W. J. and Xue, M.: Sensitivity Analysis of Convection of the 24 May 2002 IHOP Case Using Very Large Ensembles, Mon. Weather Rev., 134, 192-207, https://doi.org/10.1175/mwr3061.1, 2006.

Millán, L., Lebsock, M., Fishbein, E., Kalmus, P., and Teixeira, J.: Quantifying Marine Boundary Layer Water Vapor beneath Low Clouds with Near-Infrared and Microwave Imagery, J. Appl. Meteorol. Clim., 55, 213-225, https://doi.org/10.1175/JAMC-D-150143.1, 2016.

Millán, L., Lebsock, M., Fishbein, E., Kalmus, P., and Teixeria, J.: AMSR-MODIS Boundary Layer Water Va- 
por L3 Daily 1 degree $\times 1$ degree V2, GES DISC, https://doi.org/10.5067/MEASURES/AMDBLWV2, 2018a.

Millán, L., Lebsock, M., Fishbein, E., Kalmus, P., and Teixeria, J.: AMSR-MODIS Boundary Layer Water Vapor L3 Monthly 1 degree $\times 1$ degree V2, GES DISC, https://doi.org/10.5067/MEASURES/AMMBLWV2, 2018b.

Muhlbauer, A., McCoy, I. L., and Wood, R.: Climatology of stratocumulus cloud morphologies: microphysical properties and radiative effects, Atmos. Chem. Phys., 14, 6695-6716, https://doi.org/10.5194/acp-14-6695-2014, 2014.

Platnick, S., King, M. D., Meyer, K. G., Wind, G., Amarisinghe, N., Marchant, B., Arnold, G. T., Zhang, Z., Hubanks, P. A., Ridgway, B., and Riedi, J.: MODIS Cloud Optical Properties: User Guide for the Collection 6 Level-2 MOD06/MYD06 Product and Associated Level-3 Datasets, 1, 1-145, available at: https://modis-images.gsfc.nasa.gov/_docs/ C6MOD06OPUserGuide.pdf (last access: December 2018) 2015.

Randall, D., Wood, R. A., Bony, S., Colman, R., Fichefet, T., Fyfe, J., Kattsov, V., Pitman, A., Shukla, J., Srinivasan, J., Stouffer, R. J., Sumi, A., and Taylor, K. E.: Climate models and their evaluation., book section 8, pp. 589-662, Cambridge University Press, Cambridge, ULK and New York, NY, USA, 2007.

Richter, I.: Orographic influences on the annual cycle of Namibian stratocumulus clouds, Geophys. Res. Lett., 31, L24108, https://doi.org/10.1029/2004gl020814, 2004.

Richter, I. and Mechoso, C. R.: Orographic Influences on Subtropical Stratocumulus, J. Atmos. Sci., 63, 2585-2601, https://doi.org/10.1175/jas3756.1, 2006.

Sandu, I., Stevens, B., and Pincus, R.: On the transitions in marine boundary layer cloudiness, Atmos. Chem. Phys., 10, 2377-2391, https://doi.org/10.5194/acp-10-2377-2010, 2010.

Seidel, D. J., Ao, C. O., and Li, K.: Estimating climatological planetary boundary layer heights from radiosonde observations: Comparison of methods and uncertainty analysis, J. Geophys. Res., 115, D16113, https://doi.org/10.1029/2009jd013680, 2010.

Stull, R. B. (Ed.): An Introduction to Boundary Layer Meteorology, https://doi.org/10.1007/978-94-009-3027-8, Springer the Netherlands, 1988.

Teixeira, J.: Simulation of fog with the ECMWF prognostic cloud scheme, Q. J. Roy. Meteor. Soc., 125, 529-552, https://doi.org/10.1002/qj.49712555409, 1999.

Teixeira, J., Cardoso, S., Bonazzola, M., Cole, J., DelGenio, A., DeMott, C., Franklin, C., Hannay, C., Jakob, C., Jiao, Y., Karlsson, J., Kitagawa, H., Köhler, M., Kuwano-Yoshida, A., LeDrian, C., Li, J., Lock, A., Miller, M. J., Marquet, P., Martins, J., Mechoso, C. R., v. Meijgaard, E., Meinke, I., Miranda, P. M. A., Mironov, D., Neggers, R., Pan, H. L., Randall, D. A., Rasch, P. J., Rockel, B., Rossow, W. B., Ritter, B., Siebesma, A. P., Soares, P. M. M., Turk, F. J., Vaillancourt, P. A., Engeln, A. V., and Zhao, M.: Tropical and Subtropical Cloud Transitions in Weather and Climate Prediction Models: The GCSS/WGNE Pacific CrossSection Intercomparison (GPCI), J. Climate, 24, 5223-5256, https://doi.org/10.1175/2011jcli3672.1, 2011. von Engeln, A. and Teixeira, J.: A Planetary Boundary Layer Height Climatology Derived from ECMWF Reanalysis Data, J. Climate, 26, 6575-6590, https://doi.org/10.1175/jcli-d-12-00385.1, 2013.

Weckwerth, T. M., Wilson, J. W., and Wakimoto, R. M.: Thermodynamic Variability within the Convective Boundary Layer Due to Horizontal Convective Rolls, Mon Weather Rev., 124, 769-784, https://doi.org/10.1175/15200493(1996)124<0769:tvwtcb>2.0.co;2, 1996.

Weckwerth, T. M., Parsons, D. B., Koch, S. E., Moore, J. A., LeMone, M. A., Demoz, B. B., Flamant, C., Geerts, B., Wang, J., and Feltz, W. F.: An Overview of the International H2O Project (IHOP_2002) and Some Preliminary Highlights, B. Am. Meteorol. Soc., 85, 253-278, https://doi.org/10.1175/bams-85-2-253, 2004.

Wentz, F. J. and Meissner, T.: AMSR ocean algorithm, version 2, Remote Sensing Systems Tech. Rep. 121599A-1, 66 pp., available at: http://eospso.gsfc.nasa.gov/sites/default/files/atbd/ atbd-amsr-ocean.pdf (last access: December 2018), 2000.

Wood, R.: Stratocumulus Clouds, Mon. Weather Rev., 140, 2373 2423, https://doi.org/10.1175/mwr-d-11-00121.1, 2012.

Wood, R. and Bretherton, C. S.: On the Relationship between Stratiform Low Cloud Cover and Lower-Tropospheric Stability, J. Climate, 19, 6425-6432, https://doi.org/10.1175/jcli3988.1, 2006.

Zhou, X., Kollias, P., and Lewis, E. R.: Clouds, Precipitation, and Marine Boundary Layer Structure during the MAGIC Field Campaign, J. Climate, 28, 2420-2442, https://doi.org/10.1175/jcli-d14-00320.1, 2015.

Ziegler, C. L. and Rasmussen, E. N.: The Initiation of Moist Convection at the Dryline: Forecasting Issues from aCase Study Perspective, Weather Forecast., 13, 1106-1131, https://doi.org/10.1175/15200434(1998)013<1106:tiomca>2.0.co;2, 1998 . 